\title{
Analytical Study of Common Rigid Steel Connections under the Effect of Heat
}

\author{
Rohola Rahnavard, ${ }^{1}$ Navid Siahpolo, ${ }^{2}$ Mohammad Naghavi, ${ }^{1}$ and Akbar Hassanipour ${ }^{3}$ \\ ${ }^{1}$ Structure Engineering, Faculty of Civil Engineering, ACECR, Khuzestan, Ahvaz, Iran \\ ${ }^{2}$ Earthquake Engineering, Faculty of Civil Engineering, ACECR, Khuzestan, Ahvaz, Iran \\ ${ }^{3}$ Earthquake Engineering, Jondi Shapour University of Dezful, Dezful, Iran \\ Correspondence should be addressed to Rohola Rahnavard; rahnavard1990@gmail.com
}

Received 27 October 2014; Accepted 4 December 2014; Published 29 December 2014

Academic Editor: John Mander

Copyright (C) 2014 Rohola Rahnavard et al. This is an open access article distributed under the Creative Commons Attribution License, which permits unrestricted use, distribution, and reproduction in any medium, provided the original work is properly cited.

\begin{abstract}
One of the most important members of steel structure's connection region is beam-to-column connection. Rigid connection in steel moment frame has special role in the behavior of these structures and the fire resistance of these connections can be important. In this paper the behaviors of three common types of rigid connections in Iran under the effect of heat were studied by the use of numerical finite element methods through ABAQUS software. The models were verified by the use of an experimental model through elastic and plastic amplitudes up to collapse and during numerical results, and the effect of large deformation in the nonlinear region has also been considered. The results show that the connection with the end plate had a better performance against heat than other connections. Also reduced stiffness and lateral buckling in this connection were less than other connections.
\end{abstract}

\section{Introduction}

Steel frames are made of beams and columns that are connected to each other by connection and connection is responsible for the transfer of forces from the beamto-column connections and withstanding these forces. In order to calculate and design of connections many designers assume connection simple or rigid. Although these simplifications make the analysis and design remarkably easy in fact, the behavior of these connections in terms of rigidity is always a value between this limit; for instance, most of the connections that are assumed to be simple have hard rotational stiffness and rigid connections are also less flexible. This design method can be suitable for the connection modes at room temperature, but when fire occurs, the behavior of joints changes and they have greater impact on the behavior of structure and if in this situation this connection behavior is not treated properly, the design credit may extinct and cause serious damage to the structure. After the accident in which air plane crashed into the twin towers of world trade center, despite the fact that these buildings have been designed for extremely heavy loads and showed resistance against the collision of giant aircraft but acted poorly against the heat of the explosion and after that towers collapsed. In the past, many researchers have studied the effects of fire and heat on steel structures and the result of their researches was several laboratory tests but due to the cost of these tests and lack of complete laboratory facilities the use of numerical methods has been inevitable. Saedi Darian et al. [1-3] conducted experiments on simple connections with seat angles, in both welded and bolted states. Lawson [4] studied the rigid connection of steel under fire. His results showed that the joint behavior with concrete cover over the connection region improves against the fire. Rahnavard et al. [5] numerally examined the rigid connection of steel with the end plate connection and explained thermal modeling through ABAQUS software.

Selamet and Garlock [6] by the use of numerical modeling studied the simple connection of steel. Their study showed that the durability of bolt and hole's diameter are very important in the behavior of simple connections. Kalogeropoulos et al. [7] through ABAQUS finite element 


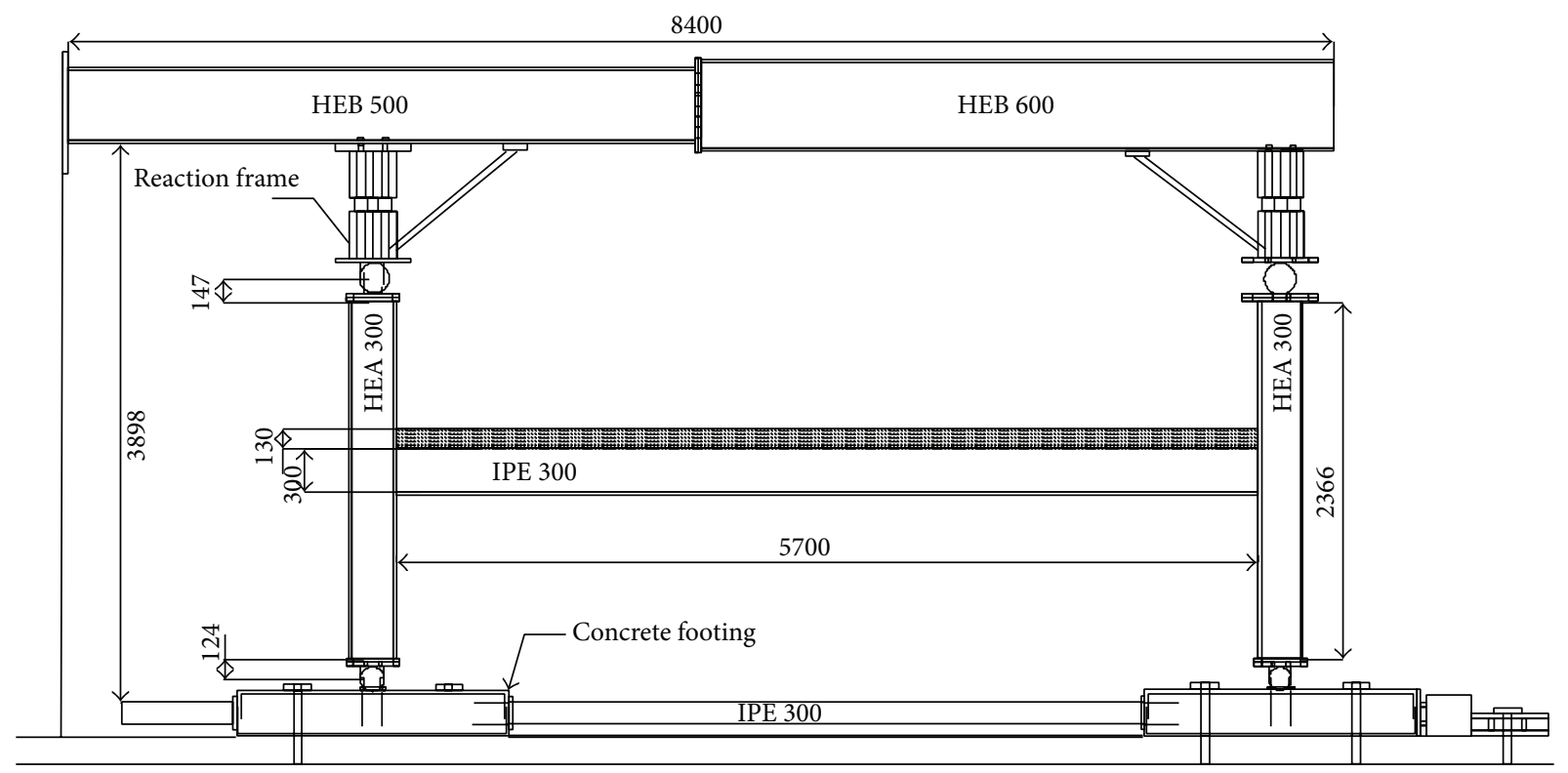

FIGURE 1: Laboratory sample [8].

software modeled bolted rigid connection plates with the end plates and assessed the influence of parameters such as mechanical loads, strength of bolts, the coefficient of friction, and the holes of bolt.

Wald et al. [8] made several experimental models of rigid end plate connection and compared failure mode and shift of the center of the beam in these models with each other. Kruppa [9] using an experimental research on several types of steel joints at elevated temperatures showed that failure of the steel members preceded failure of high strength bolts. In Burgess studied [6], an explicit dynamic solver was used. Other research projects involve study of the cooling phase of a fire [10], as well as implementation of an artificial neural network for the description of the stress-strain relations of steel under fire [11].

This study examines the common rigid connections of steel under the effect of heat and compares these connections from the view point of deformation, rotation, and stiffness.

\section{Interaction Theory}

Unilateral contact with Coulomb friction is considered at the interface between the extended end plate and the column flange and allows for possible separation of the connected parts. At each point of the interface the basic unilateral contact mechanism can be described by the no-penetration inequality, the no-tension inequality, as well as a complementarity, either-or relation, indicating that either separation with zero contact force or compressive contact force with zero gap appears. The arising nonsmooth structural analysis problem has the form of a nonlinear complementarity problem. In the tangential direction a similar either-or variable structure behavior concerning the stick-slip effects appears. In particular, the behavior in the tangential direction is defined by a static version of the Coulomb friction law. Two contacting surfaces start sliding when the shear stress in the interface reaches a critical value equal to

$$
t^{t}=\tau_{\mathrm{cr}}= \pm \mu t^{n}
$$

where $t^{t}$ and $t^{n}$ are the shear stress and the contact pressure at a given point of the contacting surfaces, respectively, and $\mu$ is the friction coefficient. There are two possible directions of sliding along an interface, so $t^{t}$ can be positive or negative depending on that direction. In principle, there is no sliding if $t^{t}<\mu t^{n}$ (stick conditions). However, for the numerical implementation of the present computational scheme, the friction constraint is enforced with the penalty method. Within this method a small sliding (approximately $0.5 \mathrm{~mm}$ ) is permitted until the shear stress $t^{t}$ becomes critical and equal to $\mu t^{n}$. For the enforcement of the contact constraints (in the normal direction of the corresponding interface), the Lagrange multipliers method has been used. Also "hard contact" is used to define interaction property in the normal direction. In addition hard contact allowed two surfaces separated from each other. The aforementioned scheme has been numerically implemented within ABAQUS computer program used here.

\section{Introducing the Details and Modeling Assumptions}

In this study through using finite element method three types of steel rigid connections were modeled. These models included screw connection with end plate: connection with bolted cover plate to beam and bolted $\mathrm{T}$ joint to the beam and column. Modeling was done in the three-dimensional form in real scale by the use of ABAQUS software and deformations 


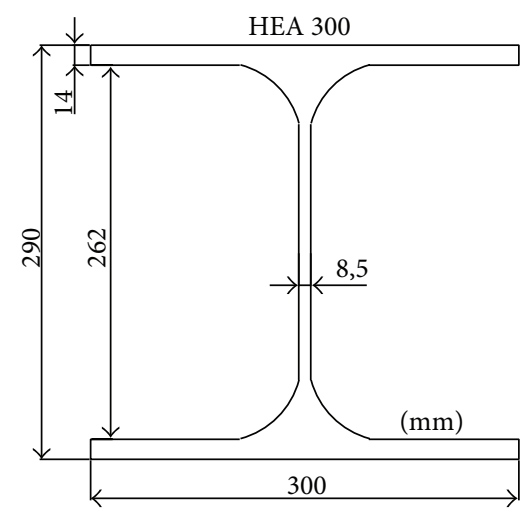

(a)

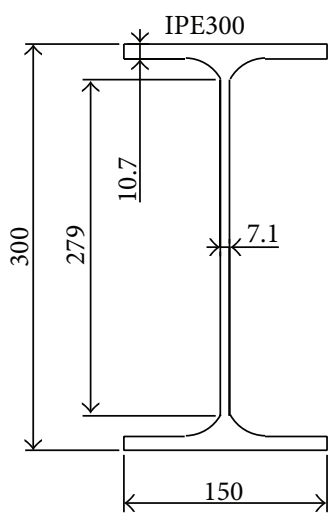

(b)

FIgURE 2: (a) Beam section; (b) column section.

of nonlinear region were used. Geometry and boundary conditions are based on the laboratory sample made by Wald et al. [8]. The height of column and length of beam were 2.4 and $5.7 \mathrm{~m}$, respectively, that in this study half of the length of the beam was modeled. Beam and column sections for all models, respectively, are IPE300 and HEA300.

Also for all bolted connections $8.8 \mathrm{M}$ bolt has been used. To simplify and reduce the numerical calculations, the concrete slab available in laboratory sample was not modeled but its effect as a massive burden on the beam and limiting the upper flange of beam has been considered. A concentrated load of $20 \mathrm{KN}$ at a distance of $700 \mathrm{~mm}$ entered on the beam flange from the midspan. Figure 1 shows the boundary conditions and geometry of laboratory sample and Figure 2 shows the beam and column sections and Figure 3 shows the details of connection.

For loading, the structure first goes under gravity loads (weight of structure and vertical loads) and then along with the presence of these loads temperature gradually entered on the beam and beam-to-column joint region. As Figure 4 shows, heat is entered into the two regions of the model. Range of heat applied to the various components of the structure is variable. Figure 5 shows the thermal loading for the various components of the structure. In order to verify the feasibility of modeling, the model of rigid end plate connection was made based on the laboratory work of [8]
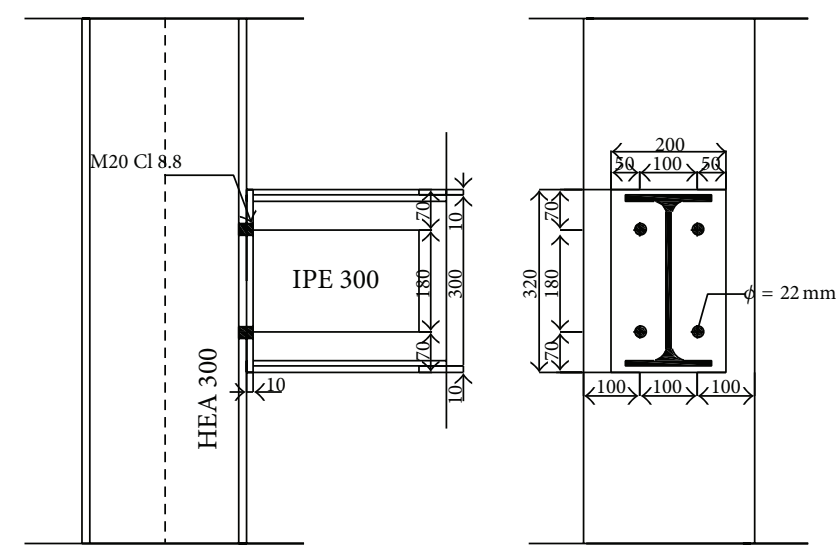

FIGURE 3: Details of the rigid connection with end plate.

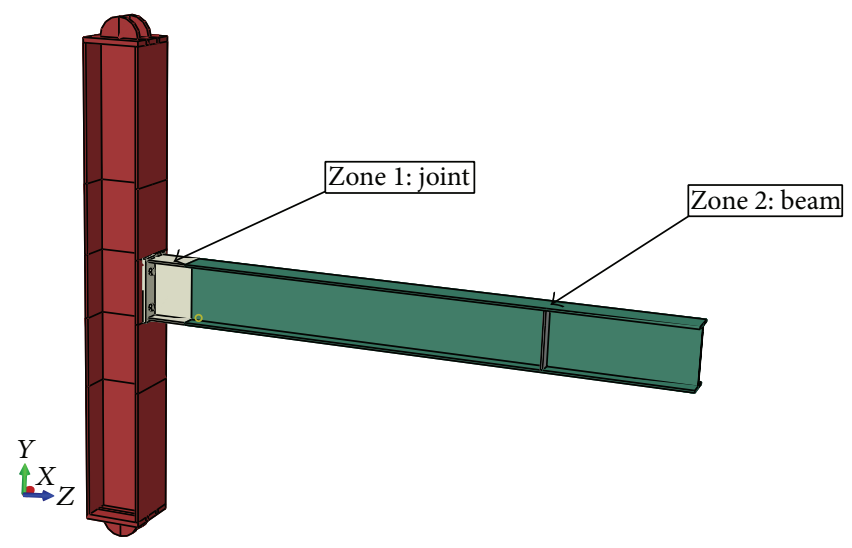

FIGURE 4: Different heated regions.

in ABAQUS software and the results of model analysis were compared with laboratory results.

To define the material properties the diagram of the stress-strain in elastic and nonelastic mood was used. It should be noted that the modulus elasticity and elastic and plastic properties change with temperature variable and theses changes have been defined to the software; also the stiffness of steel in the plastic region was considered as isotropic. For the characteristics of beam sections, columns, and plates the steel with yield stress of $388 \mathrm{MPa}$ and ultimate stress of $485 \mathrm{MPa}$ was used. Also for the bolts the steel with the yield stress of $600 \mathrm{MPa}$ and ultimate stress of $800 \mathrm{MPa}$ was used. Numerical model of bolted rigid connection with end plate is shown in Figure 6(a). To mesh this joint the C3D8T element has been used that in this element had eight nodes and each node had three degrees of freedom. Also this element uses reduced integration that greatly reduces the size of the math calculations. Contact simulation in ABAQUS software can be carried out using surface-to-surface contact, 3 -D elements. The sliding of the surfaces on each other can be considered using these elements and no penetration occurs during the loading process. Friction between the contact surfaces at the connection was modeled using the classical Coulomb model where the friction coefficient is taken as 


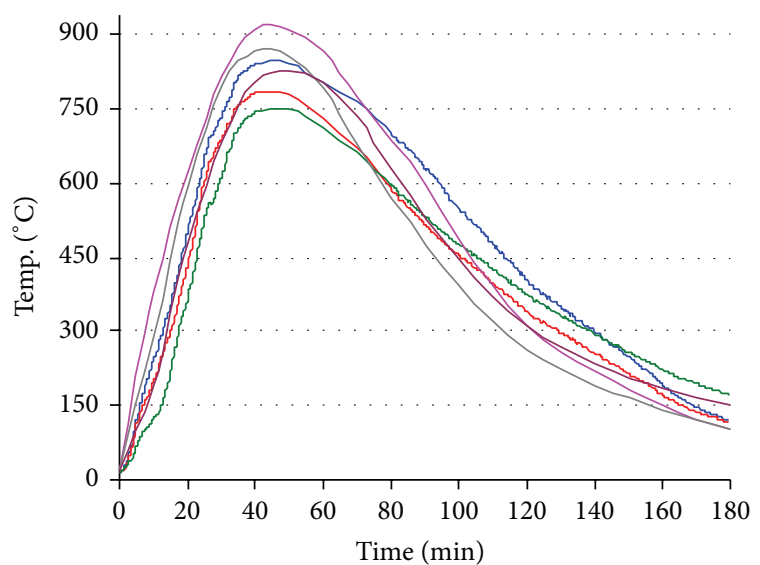

$\begin{array}{ll}\text { - Beam bottom flange (joint) } & - \text { Beam bottom flange (beam) } \\ \text { Beam web (joint) } & \text { Beam web (beam) } \\ \text { Beam top flange (joint) } & - \text { Beam top flange (beam) }\end{array}$

(a)

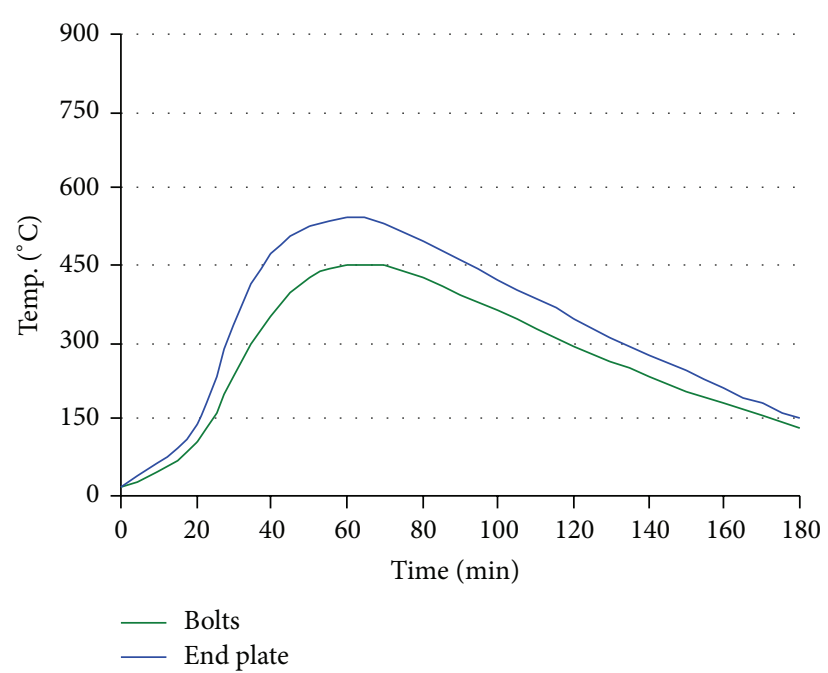

(b)

FIGURE 5: Range of heat application: (a) beam section; (b) joint region [8].

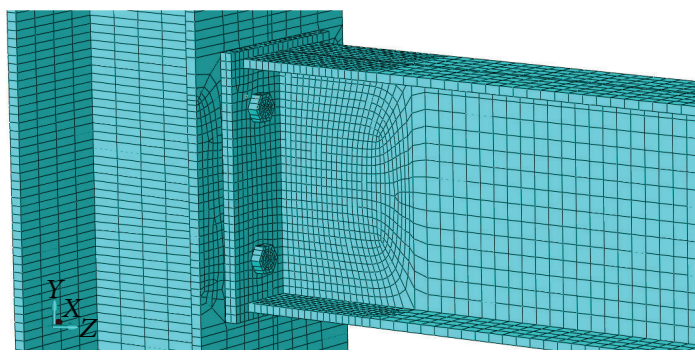

(a)

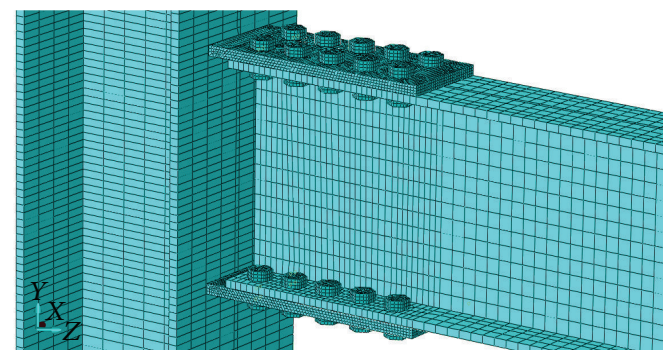

(b)

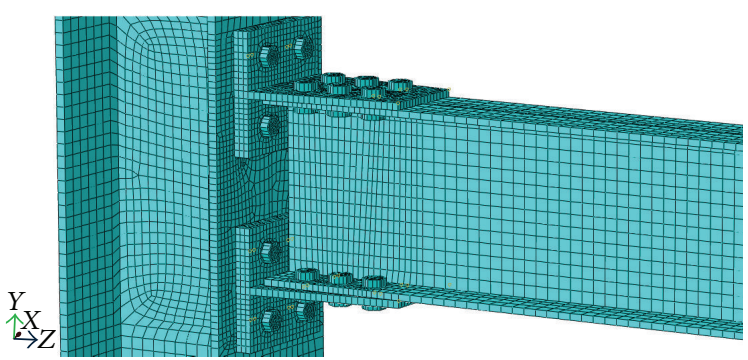

(c)

Figure 6: Mesh of studied connections: (a) connection to the end plate; (b) connection with the bolted cover plate; (c) bolted T joint.

0.2 and also hard contact used to simulation normal contact property (Table 1 ).

Figure 6 shows the close-up view of the mesh of studied joints. All these connections are designed for the same anchor (beam capacity). To analyze these models, static analysis of couple temperature-displacement was used which is appropriate for the analysis of thermal problems.

For the validation of numerical model the adaptation of displacement diagram of the midspan and the failure of laboratory sample and numerical model of bolted connection with end plate was used (Figures 7 and 9). According to Figure 7 it can be seen that the displacement of the midspan in the numerical model has a good match with the laboratory sample. Figure 8 also shows that the failure of the numerical model is much closer to the laboratory sample. Figure 9 shows the vertical displacement of the beam and the joint in laboratory status and indicates that these two are in good match. The above results show that the numerical method can be used as a reliable method.

\section{Results and Discussion}

4.1. Stress Distribution and Evaluation of Deformation. Figures 10-12 show stress distribution (von Mises criteria) 


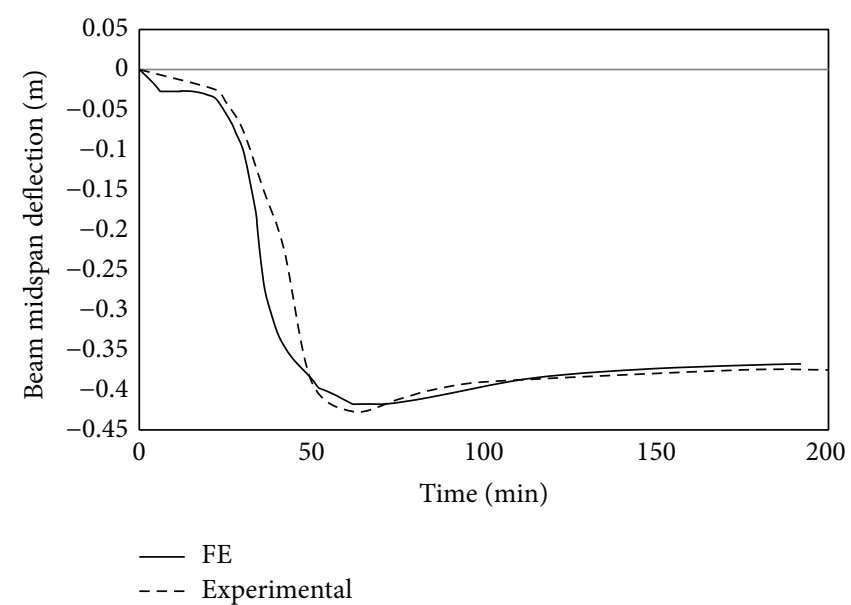

(a)

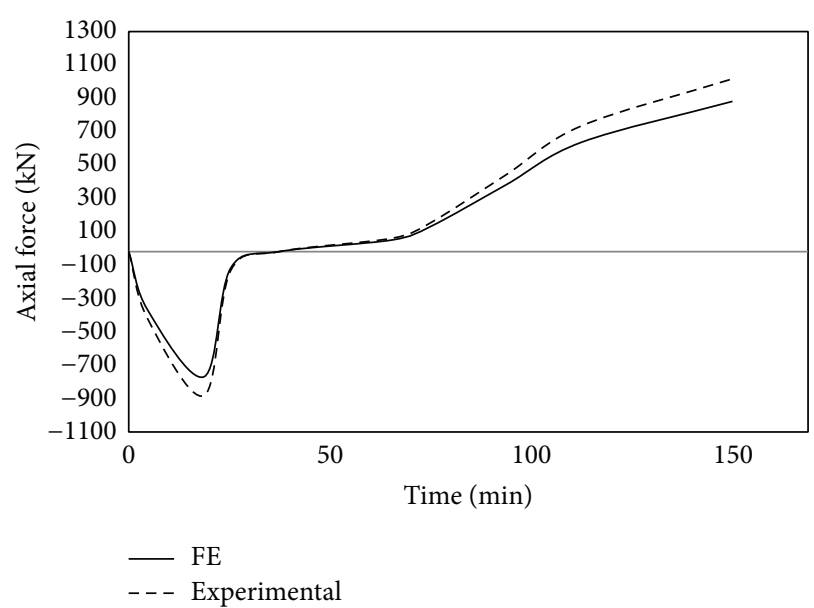

(b)

FIgURE 7: The validation of numerical models with experimental results: (a) shift of the center of the beam; (b) axial force on the screw.

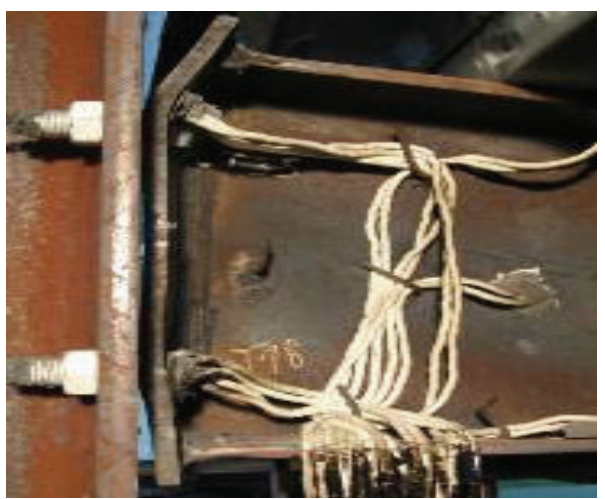

(a)

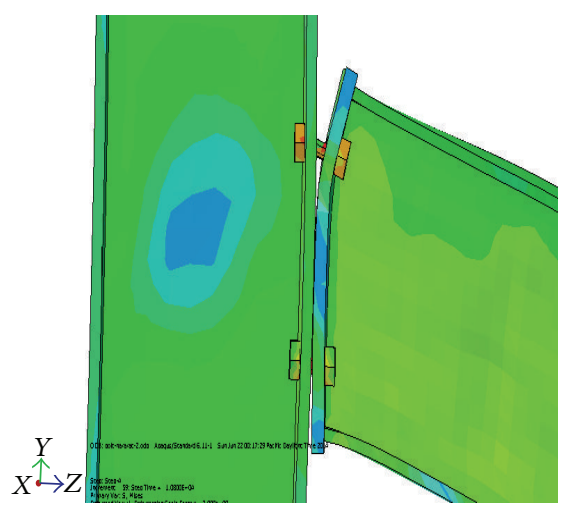

(b)

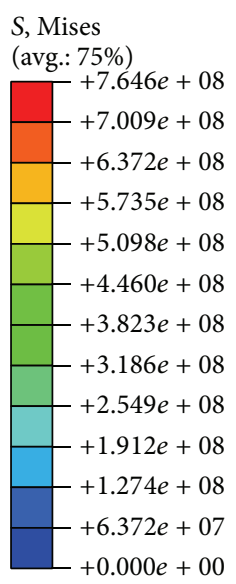

$+0.000 e+00$

FIGURE 8: Breakdown of (a) laboratory sample and (b) numerical model.

TABLE 1: Mechanical properties of the structural steel.

\begin{tabular}{lccc}
\hline Temperature $\left({ }^{\circ} \mathrm{C}\right)$ & $E(\mathrm{Gpa})$ & Fy $(\mathrm{Mpa})$ & Fu (Mpa) \\
\hline 20 & 210 & 388 & 494 \\
100 & 192 & 374 & 490 \\
200 & 189 & 439 & 571 \\
300 & 177 & 392 & 570 \\
400 & 168 & 361 & 478 \\
500 & 124 & 318 & 371 \\
600 & 105 & 215 & 222 \\
700 & 39 & 118 & 147 \\
800 & 18 & 48 & 51 \\
900 & 2 & 48 & 37 \\
1000 & 1 & 27 & 29 \\
\hline
\end{tabular}

in all models of connection for the heat to $900^{\circ}$ and no temperature (Figure (a) with heat and Figure (b) without heat). As can be seen, the deformation in all heated models is much more than without heat models. Also in models with bolted cover plate connection and bolted $\mathrm{T}$ joints (Figures 11 and 12), distortion occurs in the lower beam flange near the cover plate. The evaluation of Figures 10 to 12 shows that the presence of transverse stiffener at the length of beam can improve the beam performance against fire.

4.2. Effect of Temperature Parameter on the Vertical Displacement of the Beam. One of the most important parameters in the behavior of steel frames is the shift in the middle of the beam since the rotation of the beam-to-column connections is directly related to the shift in the middle of the beam. Since steel loses its strength against the heat quickly and behaves differently in front of the various amounts of temperature in this section the shift in the middle of the beam due to the various amounts of temperature will be discussed. To accomplish this goal, each connection was analyzed for five thermal loads. These loads include (1) the heat to 


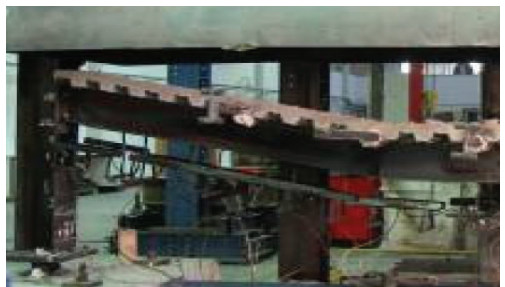

(a)

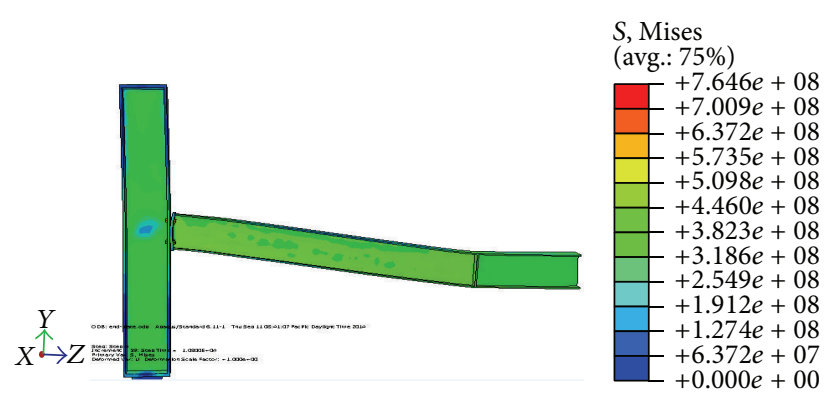

(b)

FIGURE 9: Deformation: (a) laboratory sample; (b) numerical mode.

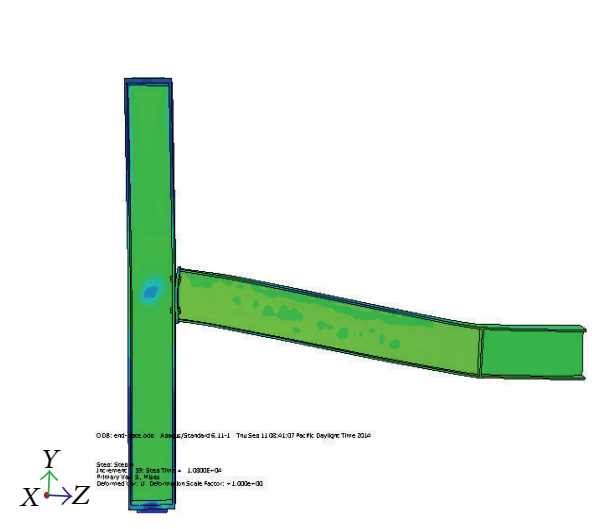

(a)

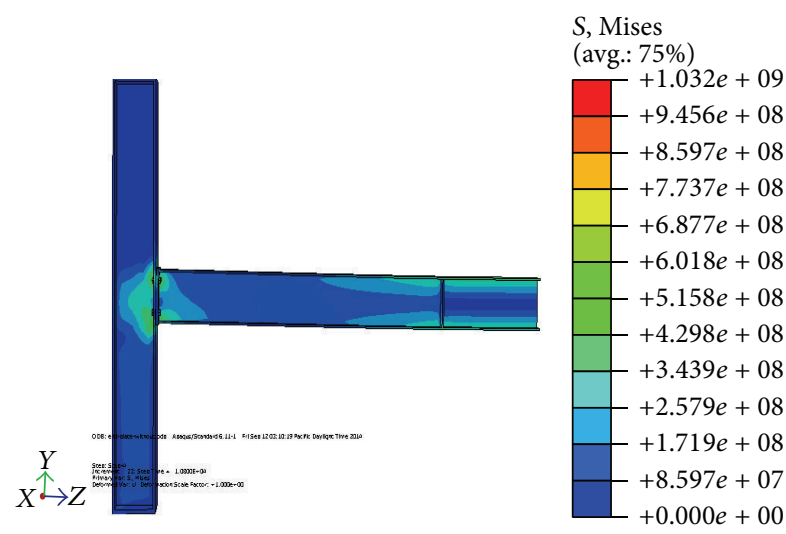

(b)

FIgURE 10: Connection to the end plate: (a) with heat and (b) without heat.

the maximum temperature of $900^{\circ} \mathrm{C}$ (full temperature), (2) joint region protection against fire and applying heat up to maximum temperature of $900^{\circ} \mathrm{C}$ to the beam (temperature on beam only), (3) heat to the maximum temperature of $450^{\circ} \mathrm{C}$ (temperature/2), (4) heat to the maximum temperature of $225^{\circ} \mathrm{C}$ (temperature/4), and (5) analysis without applying heat (without temperature).

Figures 13,14, and 15 show the shift diagram in the middle of the beam for all models under the effect of thermal loads. The results of this study about the models showed that deformation in the middle of beam in all models is strongly influenced by temperature, so that by reducing heat to half, the size of the displacement decreases more than double. In all models except the end plate connection, heat loss by half reduces the shift in the middle of beam up to four times. Also these figures show if the connection region is protected against the heat can reduce the shit up to $20 \%$. The comparison of maximum displacement in all models shows that the connections with the end plate and bolted $\mathrm{T}$ joint, respectively, have the minimum and maximum displacement.

4.3. The Out-of-Plane Buckling of Beam Web. Lateral strength in connection region against the lateral buckling is one of the most important parameters of the connection. Figures 16-18 show the out-of-plane buckling for studied connections. As can be seen the connection with the end plate against the heat can cause beam rotation along with the beam length but buckling does not occur in it. However, for the same condition, the connection region with bolted cover plate and bolted $\mathrm{T}$ joint can cause vertical lateral buckling on the beam web. According to Figures 17 and 18 it can be seen that the buckling beam in the connection region of $\mathrm{T}$ joint is more than twice the connection with cover plate.

4.4. Temperature Curve-Beam Rotation. Steel connections should be able to prevent the fire from the rotation. Figures 19,20 , and 21 show the diagram of temperature for end plate connection, connection with bolted cover plate and bolted $\mathrm{T}$ joint. As it can be seen the rotation of connection for end plate connection, connection with bolted cover plate and connection with bolted $\mathrm{T}$ joint, respectively, increases at temperatures of 100,350 , and $500^{\circ} \mathrm{C}$ exponentially.

4.5. Stiffness Curve: Temperature for Panel Zone. One of the most important parameters in this study is to investigate the stiffness of bolted rigid connection under the effect of hat. According to Euro code 3, Part 1.2 [12] and draft 2 of Part 1.8 [13], the concentration of mass within the joint area, when compared to the connecting members, delays its temperature increase, therefore suggesting that joints could be disregarded under fire conditions. However, present numerical results have highlighted the need to evaluate the behavior of steel 


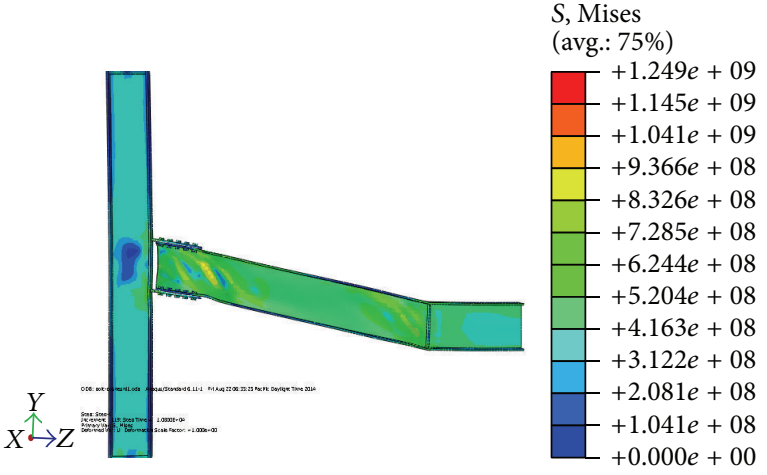

(a)

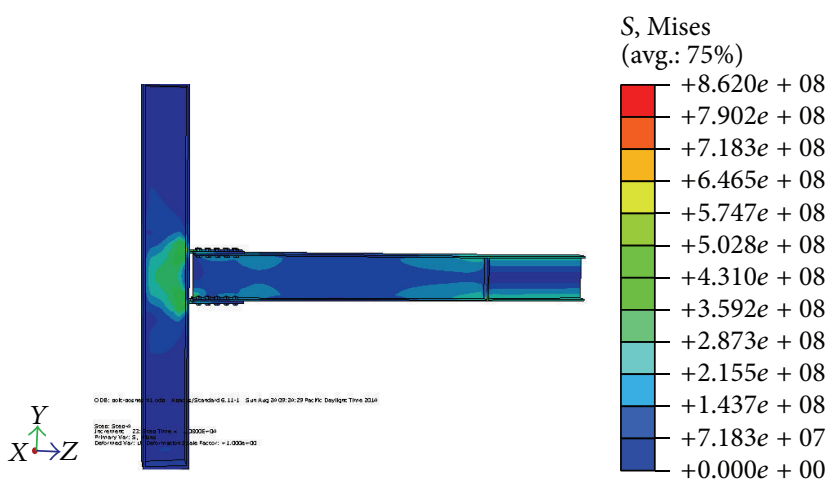

(b)

FIGURE 11: Connection with the cover plate: (a) with heat and (b) without heat.

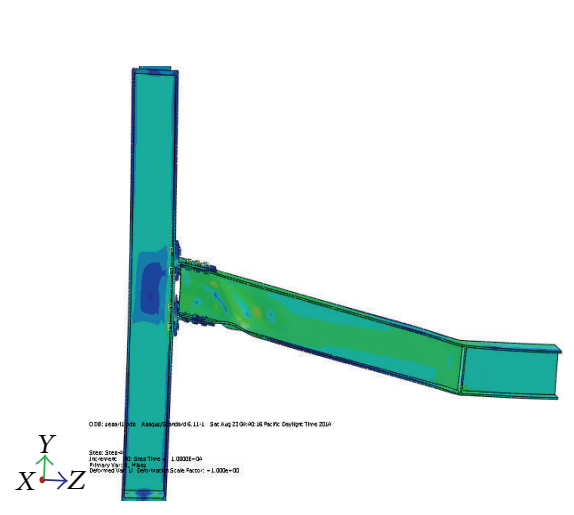

(a)
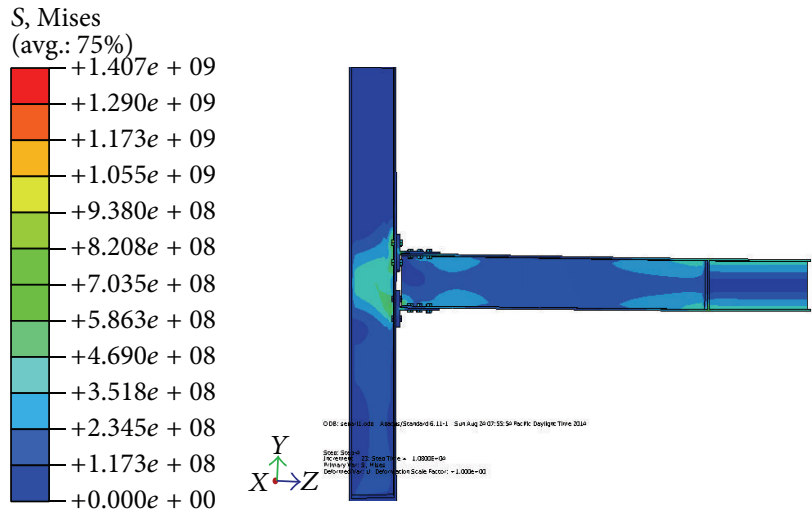

(b)

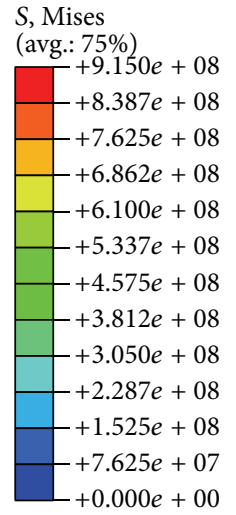

$+0.000 e+00$

FIGURE 12: T joint: (a) with heat and (b) without heat.

joints at elevated temperatures, since they exhibit a pronounced reduction of strength and stiffness that clearly affects the global response of the structure. To calculate the stiffness of the connection the following equation can be used [3]:

$$
K=\frac{M_{b}}{\Delta \theta_{r}}
$$

$$
\begin{aligned}
\Delta \theta_{r} & =\theta_{r}^{b}-\theta_{r}^{c} \\
& =\tan ^{-1}\left(\frac{\Delta_{b f}^{t}-\Delta_{b f}^{b}}{h_{b f}}\right)-\tan ^{-1}\left(\frac{\Delta_{c w}^{t}-\Delta_{c w}^{b}}{h_{b f}}\right)
\end{aligned}
$$

where $\theta_{r}^{b}$ is the rotation of beam, $\theta_{r}^{c}$ rotation of column, $\Delta_{b f}^{b}$ is horizontal displacement of the middle point of lower flange of beam to the middle point of beam web in beam-to-column connection, $\Delta_{b f}^{t}$ is the horizontal displacement of middle point of upper flange of beam to the middle point of beam web in beam-to-column connection, $\Delta_{c w}^{b}$ is the horizontal displacement of middle point of lower flange of beam at the center of column, $\Delta_{c w}^{t}$ is the horizontal displacement of the middle point of upper flange of beam at the center of column, and $h_{b f}$ is the distance of center to center of beam flanges.
Figure 22 shows the necessary parameters for calculating the stiffness of the connection. Figure 23 shows the diagram of stiffness-temperature for connection with the end plate which first increases and then decreases. The maximum stiffness for this connection occurs at 40 degrees that is equal to 100 mega newton meters/radian. The stiffness of this connection at 100 degrees reaches its lowest value, that is, 37 mega newtonmeters/radian. This stiffness is acceptable for the steel structures that have been exposed to the fire; also the main reason for the stiffness reduction in the initial moments was due to the increase in heat. Figure 24 shows stiffness-rotation diagram for the connection with the bolted cover plate. As can be seen when the heat applying starts the stiffness of connection with bolted cover loses its stiffness and therefor the value of stiffness at 300 degrees reaches its lowest value, that is, 10 meganewton meters/radian. Figure 25 shows the stiffness-rotation diagram for the bolted $\mathrm{T}$ joint which first increases and then decreases. The maximum stiffness for this connection occurs at the temperature of 180 degrees which is equal to 189 meganewton meters/radian. The stiffness of this connection at 300 degrees reaches its lowest value, that is, 62 meganewton meters/radian, and at the temperature of $450^{\circ} \mathrm{C}$ increased slightly and remained constant. This stiffness is highly appropriate for the steel structures that are exposed 


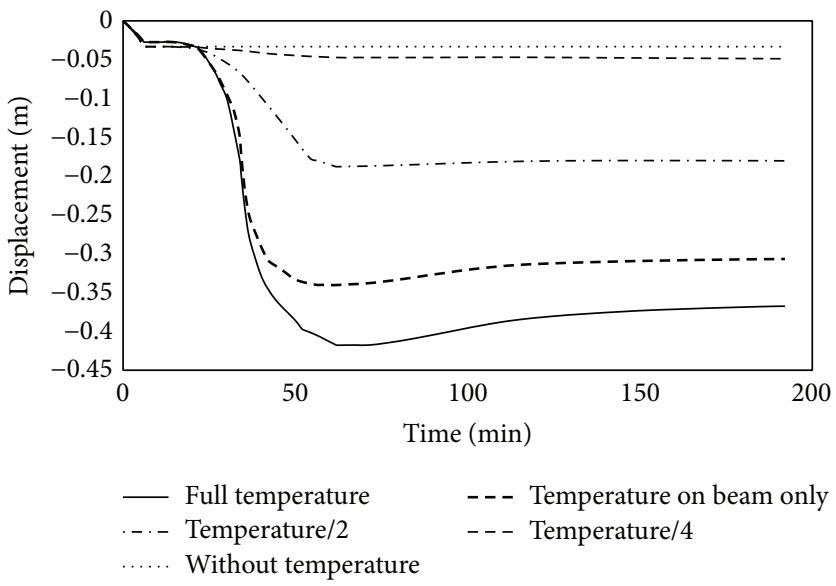

FIGURE 13: Shift diagram in the middle of the beam for connection to the end plate.

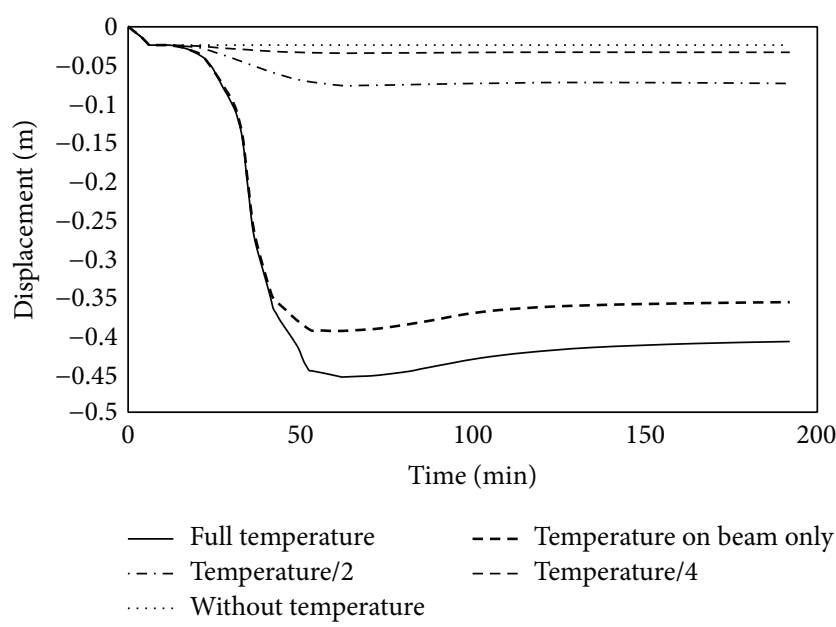

FIGURE 14: Shift diagram in the middle of the beam for connection to the bolted cover plate.

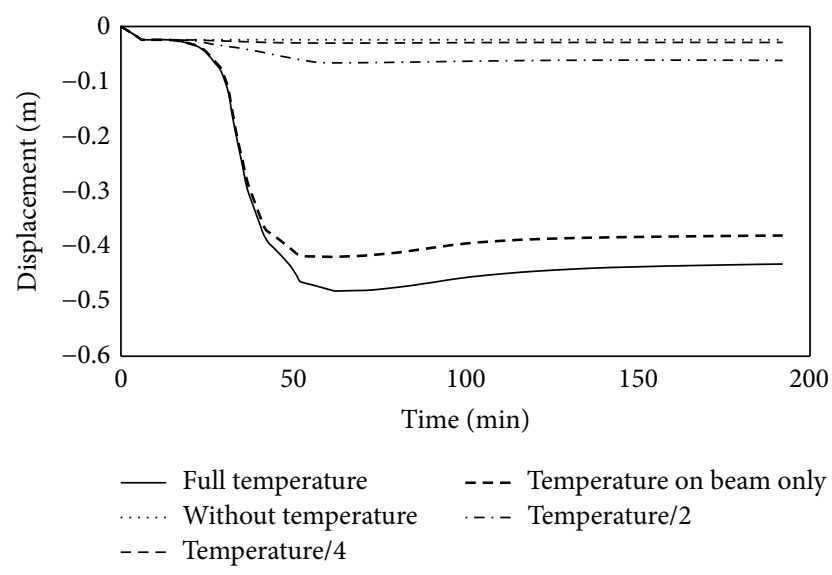

FIGURE 15: Shift diagram in the middle of the beam for connection to the bolted $\mathrm{T}$ joint.

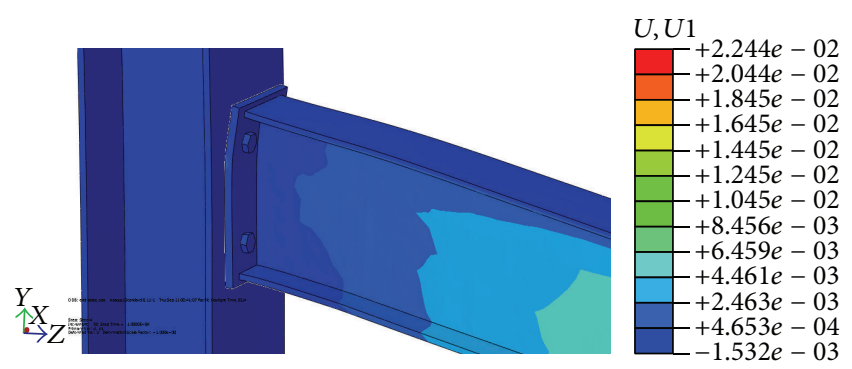

FIGURE 16: Out-of-plane buckling of the beam web for connection to the end plate.

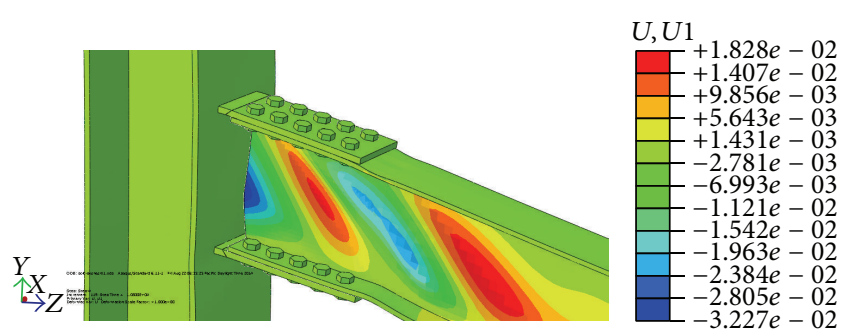

FIGURE 17: Out-of-plane buckling of the beam web for connection to the bolted cover plate.

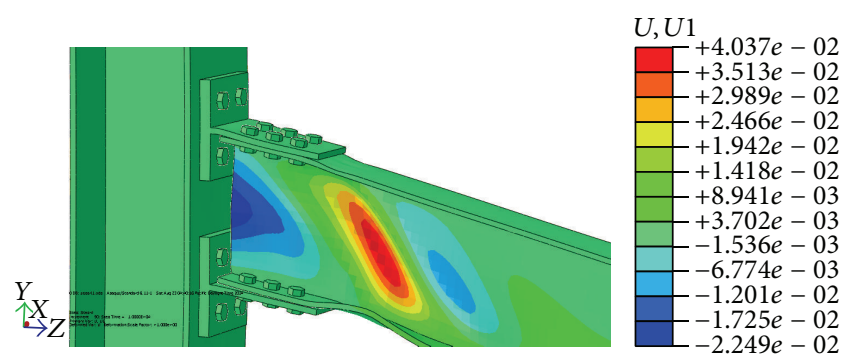

FIGURE 18: Out-of-plane buckling of the beam web for connection to the bolted $\mathrm{T}$ joint. 


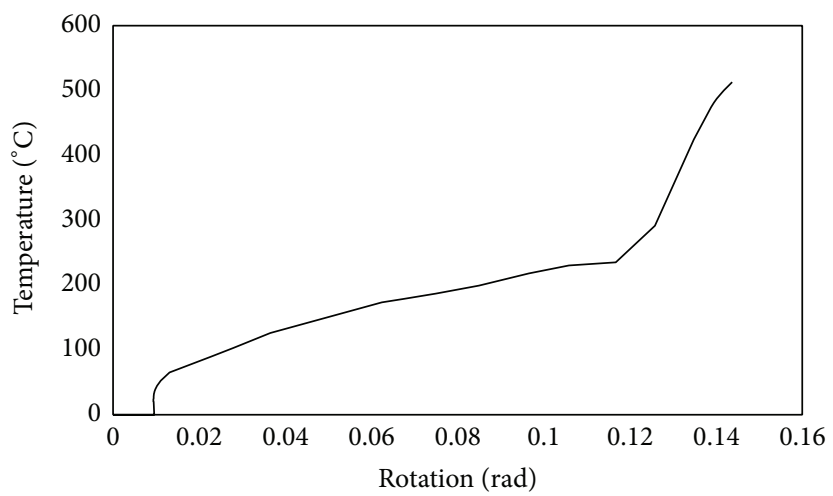

FIGURE 19: The temperature graph: the rotation of connection with the end plate.

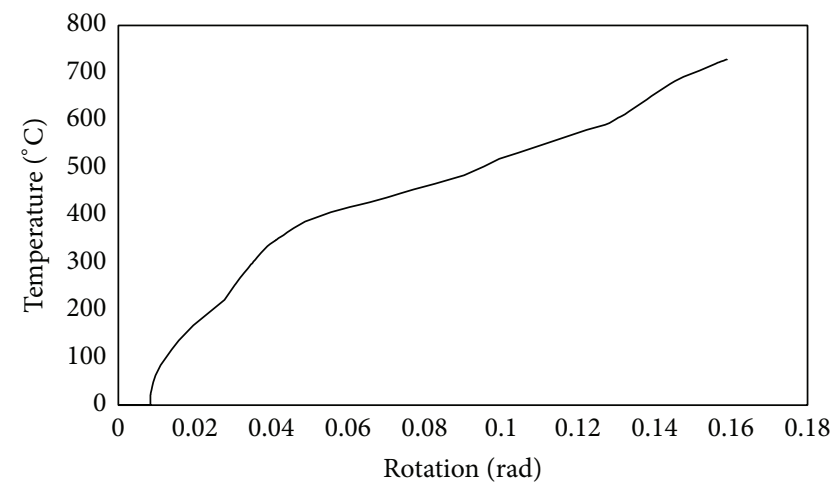

Figure 20: The temperature graph: the rotation with the bolted cover plate.

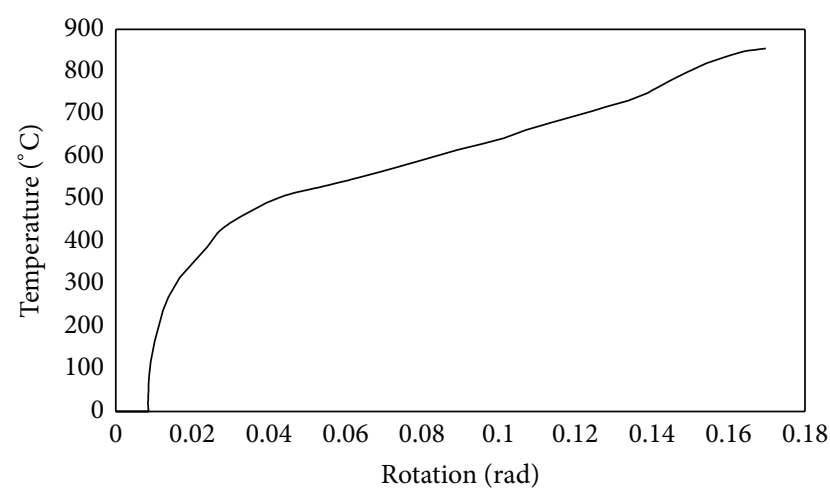

FIGURE 21: The temperature graph: the rotation with bolted $\mathrm{T}$ joint.

to the fire. Also through comparing the stiffness of these three connections it can be understood that the more the cross section of the beam-to-column connection is the better the distribution of tension on panel zone occurs and since the stiffness of panel zone is more it reduces with delay. The proportion of minimum stiffness in the case of applying heat to maximum stiffness for the connection with the end plate, plate cover connection, and $\mathrm{T}$ joint is $0.37,0.10$, and 0.30 , respectively, which indicate that the decrease in stiffness is less than the maximum stiffness in connection with end plate.

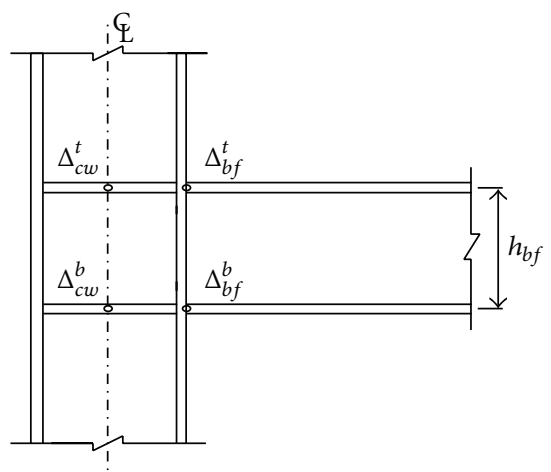

Figure 22: Parameters needed to calculate the stiffness of the connection.

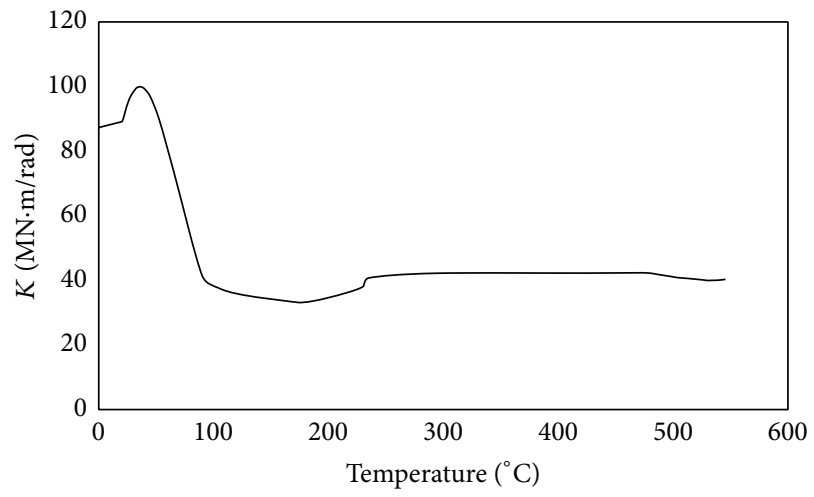

FIGURE 23: Diagram of stiffness: temperature for the connection with the end plate.

\section{Results}

The results presented in this study can be summarized as follows.

The modeling of steel connections by using numerical methods can well display their behavior when affected by the heat. Using static analysis of couple temperature, displacement results in a very good approximation. The connection region and panel zone can reduce the shift in the middle beam up to $20 \%$ when they are completely isolated against 


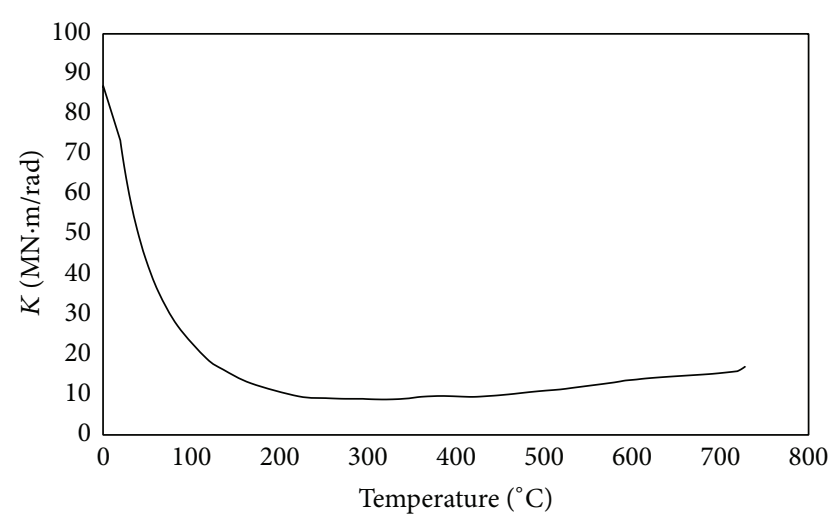

FIGURE 24: Diagram of stiffness: temperature for the connection bolted cover plate.

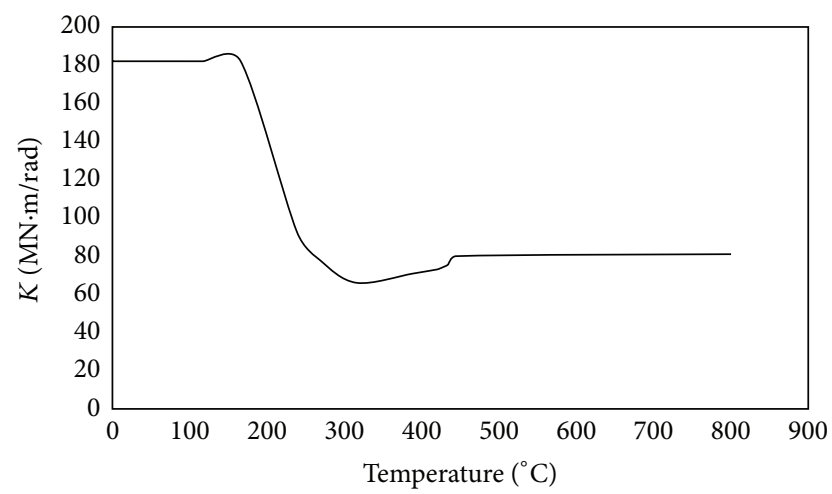

FIGURE 25: Diagram of stiffness: temperature for the bolted $\mathrm{T}$ joint.

the heat. The displacement of a steel structure is because of the main steel members exposed to fire. The connection with the end plate has better performance than other common steel connections.

Torsion can occur in all connections while in this connection only vertical displacement occurs. Steel structures are extremely heat-sensitive and in some connections when heat decreases to half the shift in the middle of the beam decreases up to four times. The stiffness of steel connections is very sensitive to the heat changes so that an increase in the heat of stiffness can drastically reduce connection. End plate connection against the heat has an efficient performance and loss of stiffness in it is less than other connections. Lateral buckling can occur in some steel connections against the high temperatures. However, the results of this study showed that end plate connection only rotated and had no lateral buckling.

\section{References}

[1] A. Pirmoz, A. S. Khoei, E. Mohammadrezapour, and A. S. Daryan, "Moment-rotation behavior of bolted top-seat angle connections," Journal of Constructional Steel Research, vol. 65, no. 4, pp. 973-984, 2009.

[2] M. Yahyai and A. S. Daryan, "The study of welded semi-rigid connections in fire," The Structural Design of Tall and Special Buildings, vol. 22, no. 10, pp. 783-801, 2011.

[3] A. Saedi Darian and A. Rezayi Far, "Investigating the effects of fire on the behavior of bolted connection with seat angles in steel structures by numerical method and its comparison with obtained laboratory results," in Proceedings of the 6th National Conference on Engineering, Semnan University, Semnan, Iran, 2012.

[4] R. M. Lawson, "Behaviour of steel beam-to-column connections in fire," Structural engineer London, vol. 68, no. 14, pp. 263271, 1990

[5] R. Rahnavard, M. Kahzadiyan, and A. H. Pour, "Investigating the effects of fire on the behavior of steel bolted rigid connection in both fixed and friction states using numerical method," in Proceedings of the National Congress of Civil Engineering, Babylon, Iran, 2014.

[6] S. Selamet and M. E. Garlock, "Robust fire design of single plate shear connections," Engineering Structures, vol. 32, no. 8, pp. 2367-2378, 2010.

[7] A. Kalogeropoulos, G. A. Drosopoulos, and G. E. Stavroulakis, "Thermal-stress analysis of a three-dimensional end-plate steel joint," Construction and Building Materials, vol. 29, pp. 619-626, 2012.

[8] F. Wald, L. Simões da Silva, D. B. Moore et al., "Experimental behaviour of a steel structure under natural fire," Fire Safety Journal, vol. 41, no. 7, pp. 509-522, 2006.

[9] J. Kruppa, "Résistance en feu des assemblages par boulous," CTICM Report 1013-1, Centre Technique Industrial de la Construction Metallique, St. Re'my les Chevreuse, France, 1976.

[10] H. Yu, I. W. Burgess, J. B. Davison, and R. J. Plank, "Numerical simulation of bolted steel connections in fire using explicit dynamic analysis," Journal of Constructional Steel Research, vol. 64 , no. 5, pp. 515-525, 2008.

[11] T. Hozjan, G. Turk, and S. Srpčič, "Fire analysis of steel frames with the use of artificial neural networks," Journal of Constructional Steel Research, vol. 63, no. 10, pp. 1396-1403, 2007.

[12] Eurocode 3, "Design of steel structures part 1.2: general rules structural fire design," ENV 1993-1-2, European Committee for Standardization, Brussels, Belgium, 2001.

[13] Eurocode 3, prEN-1993-1-8: 20, Part 1.8: Design of joints. Eurocode 3: Design of steel structures, draft 2 rev, European Committee for Standardisation, Brussels, Belgium, 2000.

\section{Conflict of Interests}

The authors declare that there is no conflict of interests regarding the publication of this paper. 

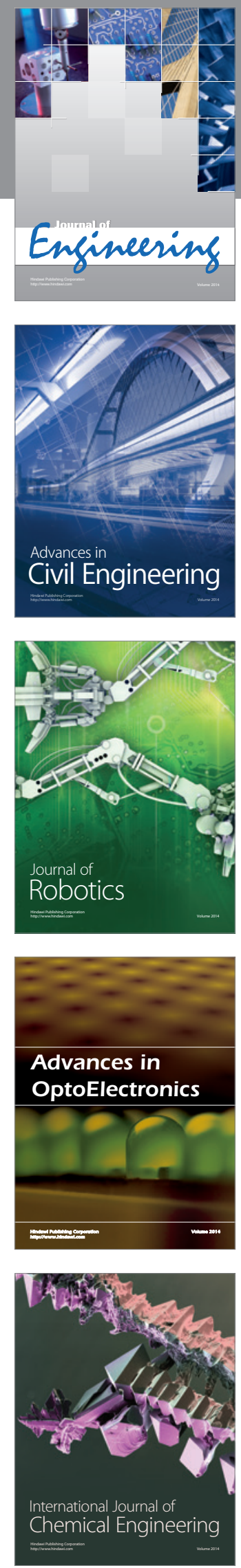

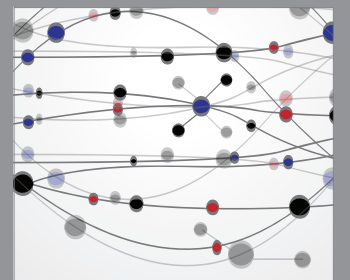

The Scientific World Journal
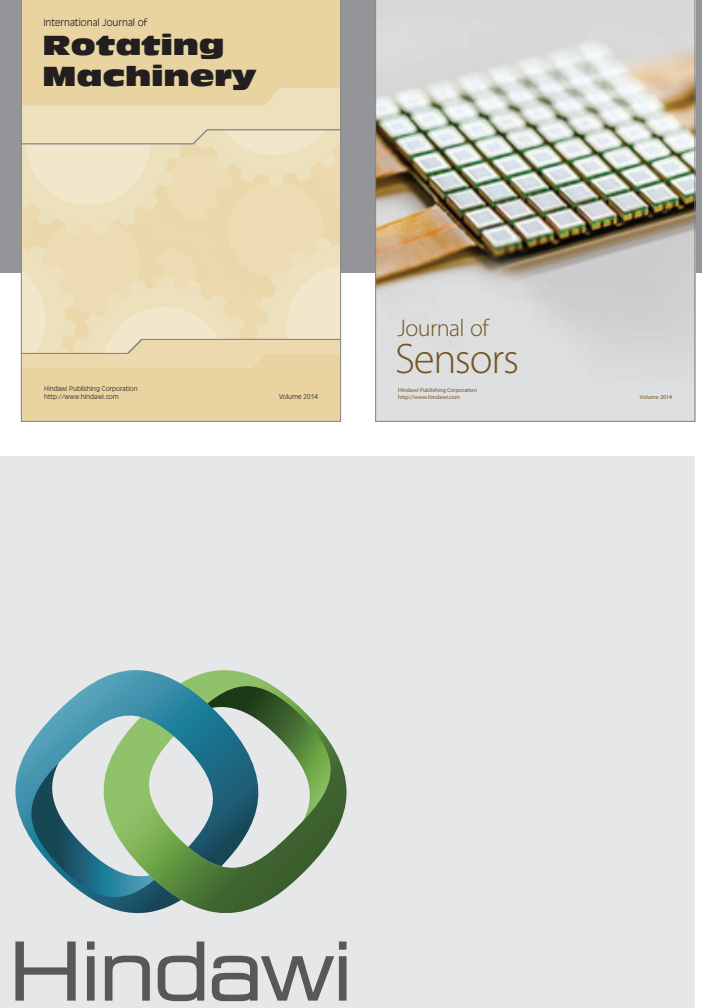

Submit your manuscripts at http://www.hindawi.com
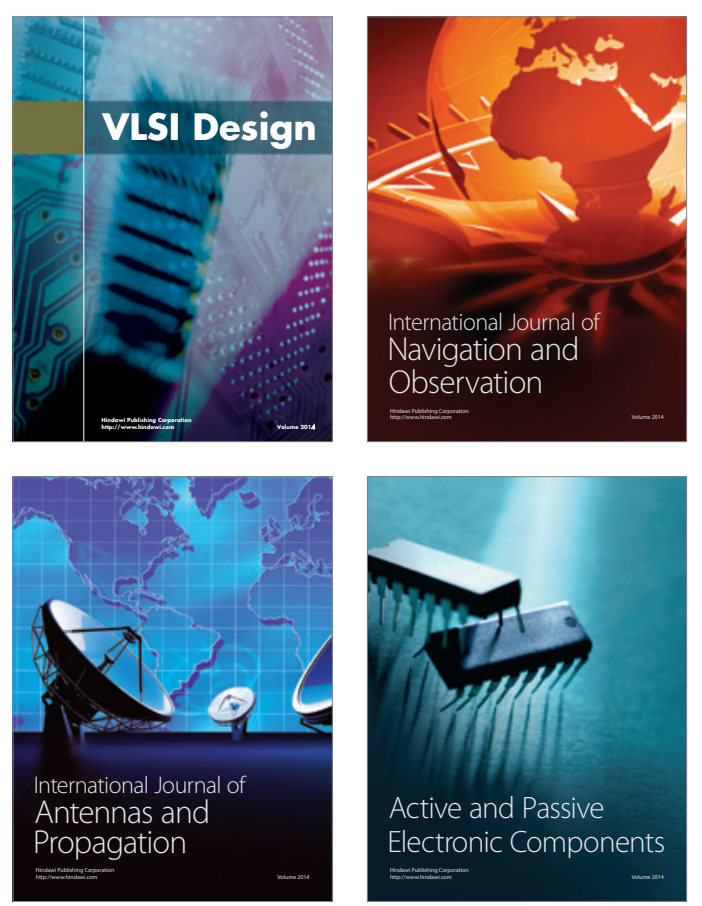
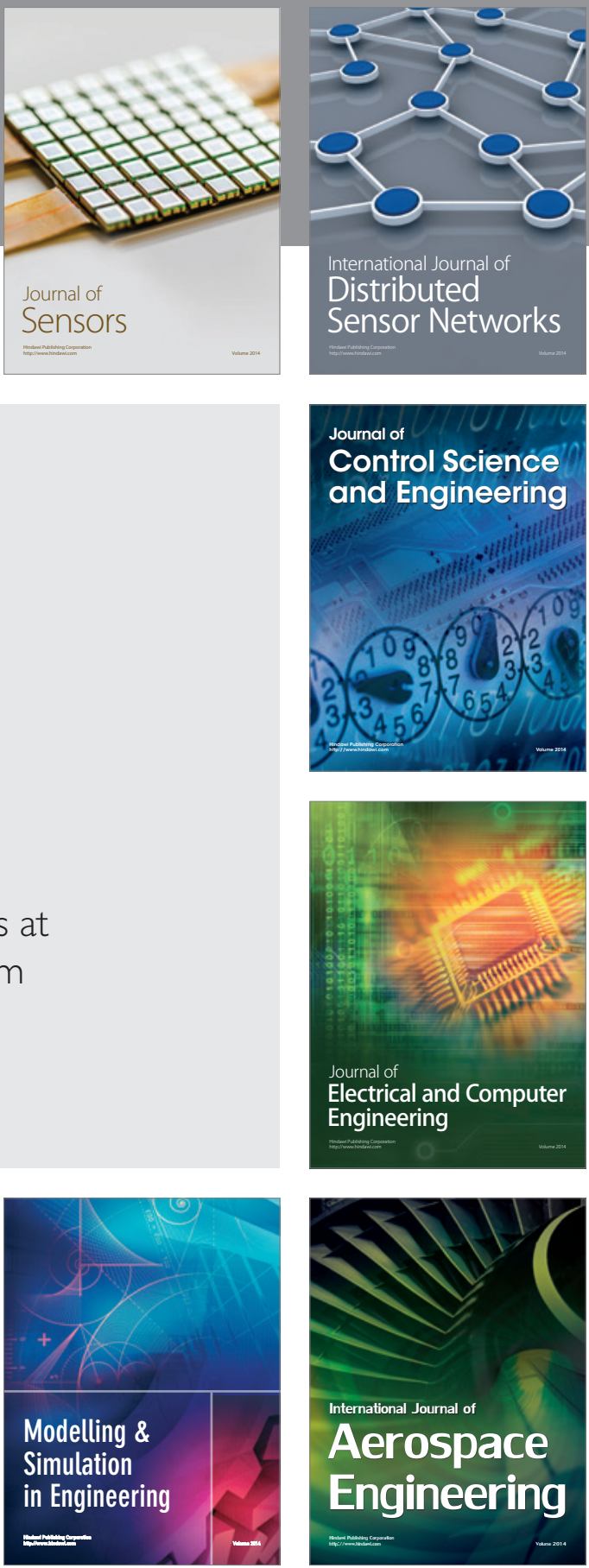

Journal of

Control Science

and Engineering
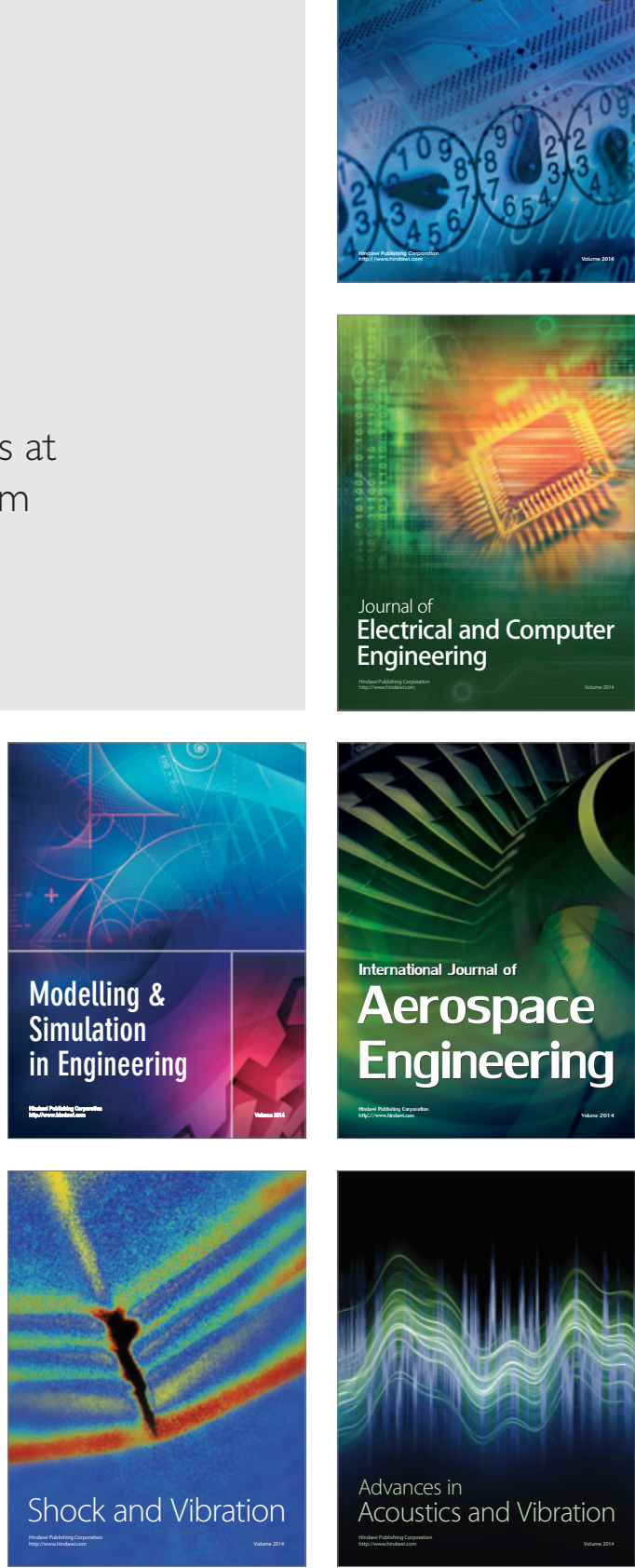